\title{
A PROPOSED IMPACT ASSESSMENT FRAMEWORK ON TV WHITESPACES TECHNOLOGIES IN RURAL HEALTHCARE: A NAMIBIAN CASE
}

\author{
Ronald Karon ${ }^{1}$, Mqhele Dlodlo ${ }^{1}$ and Nomusa Dlodlo ${ }^{2}$ \\ ${ }^{1}$ University of Cape Town, South Africa \\ ${ }^{2}$ Rhodes University, South Africa
}

\begin{abstract}
The introduction of TV Whitespaces (TVWS) technology has enabled the use of local TV bands by wireless devices for broadband internet access. Increasingly it has become important to provide internet access to rural communities. Africa has only seen a $7 \%$ internet penetration. Namibia like some other African countries has rural communities that are spread out sparsely throughout the country with vast distances between most communities. Despite access to modern telecommunications infrastructure in the country, access to broadband connections in rural areas is limited. Supporting healthcare services by using ICT for quality healthcare delivery is a growing need in rural and remote communities. Considering the above, the problem is that telehealth services cannot be adequately supported in rural or remote healthcare because of limited internet access. Furthermore, no framework exists to assess the impact of TVWS technologies in Namibian rural healthcare. Therefore, this paper proposes to address the gap of limited internet access for telehealth in Namibian rural communities, by introducing TVWS technologies in rural healthcare towards developing an impact assessment framework. The selected research paradigm for this study will be the Pragmatic paradigm. The research design will consist of a mixed-method approach, namely quantitative and qualitative. The study will consist of two phases. The first phase of the research will be an experimental approach (Positivist) which supports methods of quantitative data collection. Aspects of Human-Computer Interactions towards an impact assessment framework, will be the second phase of the study. Data gathering of a qualitative nature (Interpretivism) from participants of the public healthcare institution, would be enabled by this approach. A rural health clinic in Namibia would be used as a case study. Literature sampling, experiments, questionnaires, and semi-structured interviews will be used as data collection instruments for this research study. For the analysis of data, the first phase of the study, the implemented TVWS network and the telehealth application would be tested for robustness, usefulness and user-friendliness. The testing would be guided by benchmarks such as availability, reliability, scalability and stability. Grounded theory would be selected as the guiding theory for the second part of the study, which would lead to the development of an impact assessment framework. Preliminary findings from literature sampling indicated that the largest TVWS trial project was deployed in Namibia in 2013. The project used Adaptrum's white spaces radios with connection distances between $8 \mathrm{~km}$ and $12 \mathrm{~km}$. The throughput that was achieved ranged between $5 \mathrm{Mbps}$ to $10 \mathrm{Mbps}$. The findings suggest that a telehealth application could be tested on a TVWS network that could contribute towards the development of an impact assessment framework.
\end{abstract}

\section{KEYWORDS}

TV Whitespaces, Health Information Systems, Community Based Networks

\section{INTRODUCTION}

The introduction of TV Whitespace (TVWS) technology has enabled the use of local TV bands by wireless devices for broadband internet access. The use of TVWS indicates benefits such as long distance communications and improved barrier penetrations for areas that may be dense (Oh et al., 2014). This is due to the better propagation characteristics as it uses the Very High Frequency (VHF) and Ultra High Frequency (UHF) spectrum bands. Thus, the superior propagation characteristics best suits it for rural network connectivity (Oh et al., 2014). The VHF and UHF bands range from $54 \mathrm{MHz}$ to $698 \mathrm{MHz}$ for available TV bands (Feng, 2014). TVWS were made accessible for unlicensed broadband wireless devices in 2010 by the Federal Communications Commission (FCC) in the United States of America (USA) (Feng, 2014). This 
opened up new avenues for new applications like "Super Wi-Fi, future home area networks and smart metering services", in addition to benefiting existing services (Feng, 2014).

Increasingly it has become important to provide internet access to rural communities. Africa has only seen a 7\% internet penetration at the time of the study in 2015 (Ifeoluwa et al., 2015; Kennedy et al., 2015). One area that could be aided by internet access is telehealth.

Namibia like some other African countries has rural communities that are spread out sparsely throughout the country with vast distances between most communities. Despite access to modern telecommunications infrastructure in the country, access to broadband connections in rural areas is limited (Adaptrum, 2018). This could be due to the low buying power in rural settings and high costs in bringing the needed infrastructure to poor rural areas (Thanki, 2016).

In light of the above, the problem is that telehealth services cannot be adequately supported in rural or remote healthcare because of limited internet access (Adaptrum, 2018; Kandjeke, 2012; Thanki, 2016). Furthermore, no framework exists to assess the impact of TVWS technologies in Namibian rural healthcare (MoHSS, 2010; MoHSS, 2014).

The aim of this research paper is to propose a development of a framework to assess the impact of TVWS technologies for rural healthcare in Namibia.

\section{OBJECTIVES}

The objectives outlined below are defined to aid in achieving the aim of the research paper:

1. Examine how the current telehealth applications are utilised in rural healthcare.

2. Determine the criteria for an impact assessment framework to assess the effectiveness of TVWSs through examining existing impact assessment frameworks.

3. Assess the effectiveness of a combination of TVWS and existing telehealth applications.

4. Develop a framework that assesses the impact of TVWS in Namibian rural healthcare.

\section{PRELIMINARY LITERATURE REVIEW}

\subsection{TVWS Technologies}

TV Whitespaces (TVWS) are available frequencies situated between TV channels in the Very High Frequency (VHF)) and Ultra High Frequency (UHF) range (Ifeoluwa et al., 2015). The range of these frequencies are from $54 \mathrm{MHz}$ to $806 \mathrm{MHz}$ (Ifeoluwa et al., 2015). On the electromagnetic spectrum, the VHF is situated between $30 \mathrm{MHz}$ and $300 \mathrm{MHz}$, whereas $300 \mathrm{MHz}$ and above is ascribed to the UHF spectrum range (Ifeoluwa et al., 2015). The advantage of lower frequency broadcasts is that broadcasts are carried well over long distances and through barriers. The downside is that it does not service a lot of users over the broadcasts (Ifeoluwa et al., 2015). The various power ratio values of the TV band systems are $-107 \mathrm{dBm}$ for wireless microphone, $-116 \mathrm{dBm}$ for digital TV and -94 for analog TV (Ifeoluwa et al., 2015). -114dBm was the marked power value set out for TVWS by the Federal Communications Commission (FCC) in the United States of America (USA) (Ifeoluwa et al., 2015). The purpose being to allow for secondary access to the available TV bands using low powered TVWS devices with no interferences to unavailable band users. This can be attained using the geo-location database technology which contains information about unused TV bands (Ifeoluwa et al., 2015).

\subsection{Health Information Systems in Namibia}

Links between people, technology and processes, enhancing processes for the good of healthcare services describes Health Information Systems (HIS) (Tossy, 2014). The National Health Information System (NHIS) was implemented in 1990 in Namibia (Haoses-Gorases, 2005). Its goal was to provide a large database of health information and indicators to improve healthcare service delivery (Haoses-Gorases, 2005). The government of Namibia (GRN) has prioritised proper health for its citizens, making it the base on which the 
country's progress strategies and plans should be built (Khan \& Edwards, 2012). To support this, studying the status of HIS in the country is essential. Khan and Edwards (2012), explains that the HIS is "the principal entry point for timely data and a channel for information and knowledge exchange that are critical to facilitating evidence-based planning and decision-making throughout the system". Thus, to boost healthcare service delivery, an effective functioning and integrated HIS is necessary. According to Khan and Edwards (2012), the national HIS, through the Ministry of Health and Social Services (MoHSS), are generally fragmented and disengaged from one another. These systems collect a wide spectrum of health-related information but operate mainly as standalone systems (Khan \& Edwards, 2012). There were 61 of these systems in the country, which were either paper based, electronic and/or a combination of both (Khan \& Edwards, 2012). These systems are operated by different departments as per departmental requirements and are not necessarily integrated. This leads to challenges such as duplication of health-related information.

\subsection{Community-Based Networks}

The internet bridges nations and continents. A global community is enabled by the internet, hence access to it has been deemed a basic human right by the United Nations (UN) (Vigil-Hayes, 2017). Access to the internet is a challenging factor worldwide and more so in disadvantaged or rural communities. Vigil-Hayes (2017) states that over half the global population, $53 \%$ to be exact, did not have access to the internet in 2017. The percentage was even higher for under developed countries. $85 \%$ of under developed countries lacked access to the internet. Though broadband technologies such as mobile was indicated to have the highest penetration growth globally at a $47 \%$ rate in the past ten years, it had not achieved to address all digital divide matters (Vigil-Hayes, 2017). For example only $29 \%$ of the rural communities have access to $3 \mathrm{G}$ mobile broadband and $89 \%$ of the urban communities have access to this technology (Vigil-Hayes, 2017). Factors such as sparse population density and affordability could attribute to the rural and urban digital divides. The desire to bridge the digital divide gap in these communities could have led to the design of new and improved broadband infrastructure, whereas expanding exiting broadband technologies could be a more probable solution. Such expansions with a community context is referred to as Community-Based Networks (Vigil-Hayes, 2017).

\section{RESEARCH METHODOLOGY}

\subsection{Research Design}

The selected research paradigm for this study will be the Pragmatic paradigm. The selection was based on the main research aim of the study. Mackenzie and Knipe (2006) argue that pragmatism supports the use of multiple research philosophies and focuses on the "what" and "how" of the research problem. It is also the paradigm that enable the use of mixed-methods research. Thus, the use of data collection tools from both Positivist and Interpretivist paradigms are possible with the Pragmatic paradigm. According to Ayash (2014) applying multiple approaches would "support and prove the legibility of the developed project". Additionally, a case study method will be adopted.

Considering the above selected paradigm, the research design will consist of a mixed-method approach, namely quantitative and qualitative. The study will consist of two phases. The first phase of the research will be an experimental approach (Positivist) which supports methods of quantitative data collection. This is in line with the goal of this study to set up a TVWS network for broadband connections and running a telehealth application on the network. The purpose is to test a telehealth application for usefulness and prove the robustness of TVWS networks.

Aspects of Human-Computer Interactions towards an impact assessment framework, will be the second phase of the study. Data gathering of a qualitative nature (Interpretivism) from participants of the public healthcare institution would be enabled by this approach. Interactive elements of explicit settings as opposed to numeric digits are a focus of a qualitative method (Bricki, 2007).

A rural health clinic in Namibia would be used as a case study. Experiences of participants in natural and specific settings would be captured by the researcher, which is supported by a case study method (Alexander, 2009). Experiences of participants as it relates to the TVWS broadband network and the telehealth application will be enabled. 


\subsection{Participants' Sample}

Random sampling would be applied in the selection of participants. The research population would consist of the healthcare personnel at the rural healthcare facility and participants from the rural community. The selection of participants will be based on their roles and relationship to the use of the TVWS network and telehealth application at the health clinic. Sample participants are selected in relation to Principal criteria (Ritchie \& Lewis, 2003). In this context, the participants roles and relationship to the TVWS network and the use of a telehealth application for rural healthcare access and service delivery would be the criteria.

\subsection{Data Collection}

Literature sampling, experiments, questionnaires, and semi-structured interviews will be used as data collection instruments for this research study. A TVWS network would be setup to test a telehealth application. A literature review on existing impact assessment frameworks will be carried out. The assessment criteria from these frameworks will be fed into the questionnaires and interview questions to assess the impact of introducing TVWS technologies in rural healthcare towards developing an impact assessment framework.

\subsection{Data Analysis Techniques}

In the first phase of the study, the implemented TVWS network and the telehealth application would be tested for robustness, usefulness and user-friendliness. The testing would be guided by benchmarks such as availability, reliability, scalability and stability (Ayash, 2014). The second phase of the study would analyse data by conducting a thematic and interpretive analysis for the research, using Grounded theory as a guide. These techniques would enable the researcher to gain understanding and meaning from the collected data (Noble, 2012).

\section{PRELIMINARY FINDINGS}

\subsection{Challenges and opportunities of introducing TVWS in Namibia}

This section presents limited findings from the literature sampling. In 2013, the largest TVWS trial network coverage worldwide was carried out in Namibia (Masonta et al., 2015). The network was deployed across 62 $\mathrm{km} \times 152 \mathrm{~km}$ which totaled an area of $9424 \mathrm{~km} 2$ (Adaptrum, 2018). This trial project was piloted by the MyDigitalBridge (MDB), together with Microsoft. 28 schools in the northern part of Namibia and three regional councils namely, Ohangwena, Oshana and Omusati were covered in the network (Adaptrum, 2018). National stakeholders such as Telecom Namibia, Communications Regulatory Authority of Namibia (CRAN), the ministries of education and ICT were consulted with the purpose of stationing, installing and undertaking the broadband network (Adaptrum, 2018). The project used Adaptrum's white spaces radios with connection distances between $8 \mathrm{~km}$ and $12 \mathrm{~km}$ (Masonta et al., 2015). The throughput that was achieved ranged between $5 \mathrm{Mbps}$ to $10 \mathrm{Mbps}$ (Masonta et al., 2015). TVWS broadband networks were indicated to be possible in rural areas which could support video connections, among other services (Adaptrum, 2018). The challenges encountered during the deployment of this trial were attached to the population sparsity in the northern region, however dense the population may have been. The setup had to cover a big geographical area, requiring a lot of effort. Namibia in general has rural and urban settings that are far apart from one another. Traveling long distances to the nearest service provider of any kind, such as health care or schools, is a common challenge in rural settings. According to Thanki (2016) the internet coverage in Namibia is poor. The high-income inequality in the country and costly broadband connectivity may further prevent an increase in the internet's penetration. Furthermore, bringing broadband to Namibia's uniquely dispersed population, rural areas in particular, have failed with the current technological approaches (Thanki, 2016). The current wired and wireless technologies are indicated to be very expensive for penetrating remote areas (Thanki, 2016). The investigator, Thanki (2016) states that TVWS technologies could be a solution in bringing inexpensive broadband connections to various low income rural areas. The findings suggest that a telehealth application could be tested on a TVWS network that could contribute towards the development of an impact assessment framework. 


\section{SIGNIFICANCE OF THE RESEARCH}

The proposed development of an impact assessment framework could be used to support the possible benefits associated to using TVWS technologies. Therefore, this study will address the gap of limited internet access, for telehealth in Namibian rural communities, by introducing and assessing the use of TVWS technologies, towards designing an impact assessment framework. The significance of the proposed framework would be its use in measuring the effectiveness of TVWS technologies in rural healthcare, to support decision makers in the Namibian government, on the investment and potential of TVWS technologies, more specifically for rural areas.

The contributions of this research would be: i) expanding the application of an existing impact assessment framework to TVWS technologies for telehealth services in Namibian rural healthcare, (ii) testing a telehealth application that has not been tried elsewhere before, and (iii) using the research as a tool for discovering new knowledge on the impact of new technologies on community development.

\section{CONCLUSION}

Internet access across the globe is an essential part of communities in this era. Increasingly there is a need to bridge the digital gap experienced more so in rural areas. Access to the internet enables access to information and could aid services in the healthcare for example. This is especially important in rural areas that have limited internet access. Various factors such as affordability and unemployment in rural communities could be attributed to the limited access. TVWS technologies and networks could be a solution in providing rural communities with low cost rural internet connection. Reviewed literature points to the potential benefits attributed to TVWS networks. This study partly aims to test this point by implementing a TVWS network in a rural setting. Rural communities could be supported in areas such as healthcare through access to the internet. Telehealth could be realised whereby community members could receive remote assistance via the internet using a telehealth application. Accessing various healthcare services in communities is a challenge because of the long distances and lack of transport in such areas. Thus, an assessment to determine the impact of introducing TVWS technologies in rural healthcare would be necessary in motivating the government and various stake holders in TVWS technology investments, for affordable internet access in the rural community.

\section{REFERENCES}

Adaptrum. (2018). Case Study: MyDigitalBridge Namibia , Africa Project : Citizen Connect. Retrieved June 12, 2018, from http://www.adaptrum.com/Content/docs/Adaptrum-CS-Namibia-CitizenConnect-0517.pdf

Alexander, R. C. (2009). Fostering student engagement in history through student-created digital media: A qualitative and quantitative study of student engagement and learning outcomes in 6th-grade history instruction. Proquest Dissertations and Theses, 1-236. Retrieved from https://www.learntechlib.org/p/118654/

Ayash, M. (2014). Research Methodologies in Computer Science and Information Systems. Computer Science, $2014,1-4$.

Feng, X. (2014). Wireless Networking in TV White Spaces: System Designs and Economic Models by. Proquest Dissertations and Theses, (June).

Haoses-Gorases, L. (2005). absHaoses. Retrieved from stardata.nrf.ac.za/CODATA2005/absHaoses.doc

Ifeoluwa, O., Nassir, F., Olayiwola, W. B., \& Ayeni, A. . (2015). Recent trends on Tv White Space deployments in Africa. Nigerian Journal of Technology, 34(December), 556-563. https://doi.org/http://dx.doi.org/10.4314/njt.v34i3.19

Kandjeke, J. (2012). Follow-up report of the Auditor General on the performance audit study on the MoHSS-referral system for the financial year 2008, 2009 and 2010. Retrieved from http://www.oag.gov.na/documents/20781/68207/2008++2010+Refferal+System/48f0e300-853a-4594-b48d-9fcd077ef385?version=1.1

Kennedy, R., George, K., Vitalice, O., \& Okello-Odongo, W. (2015). TV white spaces in Africa: Trials and role in improving broadband access in Africa. IEEE AFRICON Conference, 2015-Novem. https://doi.org/10.1109/AFRCON.2015.7331920

Khan, T., \& Edwards, D. (2012). Assessment of National Health Information Systems:Ministry of Health and Social Services (MOHSS), Republic of Namibia. Retrieved from http://ghpro.dexisonline.com/sites/default/files/B015 Namibia HIS_7_30_12.pdf 
Mackenzie, N., \& Knipe, S. (2006). Research dilemmas: Paradigms, methods and methodology. Issues in Educational Research, 16(2), 1-13. https://doi.org/Retrieved from ERIC

Masonta, M. ., Kola, L. ., Lysko, A. ., Pieterse, L., \& Velempini, M. (2015). Network Performance Analysis of the Limpopo TV White Space ( TVWS ) Trial Network. IEEE AFRICON Conference, 2015-Novem. https://ieeexplore.ieee.org/document/7331923

MoHSS. (2010). National Health Policy Framework 2010-2020. Retrieved from http://www.nationalplanningcycles.org/sites/default/files/country_docs/Namibia/namibia_national_health_policy_fra mework_2010-2020.pdf

MoHSS. (2014). Public private partnership framework Ministry of Health and Social Services. Retrieved from http://www.mhss.gov.na/files/downloads/c68_PPPF_A5_Booklet_Correction_REPRO2.pdf

Noble, E. M. (2012). The Role Mentoring Plays in a White Female Novice Teacher's Perceptions of Her Enculturation into a Culturally Diverse Campus. Retrieved from http://oaktrust.library.tamu.edu/handle/1969.1/ETD-TAMU-2012-0510956

Nouria Bricki, J. G. (2007). A Guide to Using Qualitative Research Methodology. Retrieved from http://fieldresearch.msf.org/msf/handle/10144/84230

Oh, S. W., Ma, Y., Tao, M., Chu, E., \& Peh, Y. (2014). An Overview and Comparison of Tv White Space Regulations Worldwide. IEEE Xplore, 1-5. https://doi.org/10.1109/TENCONSpring.2014.6862980

Ritchie, J., \& Lewis, J. (2003). QUALITATIVE RESEARCH PRACTICE A Guide for Social Science Students and Researchers. Retrieved from https://mthoyibi.files.wordpress.com/2011/10/qualitative-research-practice_a-guide-forsocial-science-students-and-researchers_jane-ritchie-and-jane-lewis-eds_20031.pdf

Thanki, R. (2016). Achieving Universal Broadband Connectivity in Namibia. Unpublished manuscript.

Tossy, T. (2014). Major Challenges and Constraint of Integrating Health Information Systems in African Countries: A Namibian Experience, 4(7). Retrieved from http://www.esjournals.org

Vigil-Hayes, M. (2017). Spectrum Sharing in White Spaces. University of California Santa Barbara. Retrieved from https://digital.lib.washington.edu/researchworks/handle/1773/33154 